\title{
Snow Cover Model for Global Climate Simulations
}

\author{
BETtina Loth AND HaNs-F. GRAF \\ Max-Planck-Institut für Meteorologie, Hamburg, Germany
}

JOSEF M. OBERHUBER

Meteorologisches Institut, Universität Hamburg, Germany

\begin{abstract}
Because of the high sensitivity of the climate system to anomalies of the snow cover, appropriate models of the latter are required. In this paper a one-dimensional multilayer model of a snow cover is presented combining relatively accurate model physics with minimal computer time. The model is based on the balance of mass and energy, including the important internal processes such as the diffusion of temperature and water vapor, melting and freezing, the extinction of short wave radiation, and the retention of liquid water. In order to keep the possibility of using the model on a global scale, no local parameterizations are employed. An efficient numerical scheme makes the model suitable for long-term climate studies. Integrations for Potsdam $\left(52^{\circ} \mathrm{N}, 13^{\circ} \mathrm{E}\right)$ with standard synoptic measurements over a period of six winters demonstrate good correspondence between the model results and the observed values. The most serious problem remaining is the choice of a satisfactory criterion to distinguish between snowfall and rain which strongly affects the simulation of snow depth and water equivalent.
\end{abstract}

\section{INTRODUCTION}

Both observational work [Walsh et al., 1985; Heim and Dewey, 1984] and numerical simulations [Hahn and Shukla, 1976; Barnett et al., 1988; Graf, 1989] show a high sensitivity of the atmosphere to variations in the extent and mass of accumulated snow. They give evidence to suggest that anomalies of the snow cover in particular regions of Eurasia and North America might induce complex feedback mechanisms leading to local and global climate fluctuations. In addition, snow on sea ice, causing a net cooling of air and keeping the sea ice warm and thin, affects the climate at high latitudes [Ledley, 1991]. On the other hand, variations of the snow cover might indicate climate changes due to the ability to integrate atmospheric disturbances [Flohn, 1974].

In comparison with the bare soil, various physical parameters are significantly altered by a snow cover. The surface albedo rises suddenly from 10 to $25 \%$ to values of 75 to $90 \%$ for freshly fallen snow, reducing the short wave radiation absorbed by the surface. Further, the turbulent heat fluxes are modified due to a rapid decrease of the roughness length. Typical mean values over snow, given, e.g., by Stull [1988], Garratt [1992], and König [1985], vary between $10^{-3} \mathrm{~m}$ over snow-covered farmland, $10^{-4} \mathrm{~m}$ for the Antarctic region, and $10^{-5} \mathrm{~m}$ over snow-covered flat or rolling ground.

Due to the altered albedo the net radiation and, consequently, the surface temperature are reduced, leading to a smaller amount of outgoing long wave radiation, an increased sensible heat flux into the snow, and causing a cooling of the overlying lower atmosphere. The small thermal conductivity of snow additionally prevents an efficient heat conduction from the underlying snow layers and the soil. In spring the increase of the air and soil temperature is delayed, as compared with snow-free areas, since energy is used for the melting of snow. In the case of nonfrozen soil

Copyright 1993 by the American Geophysical Union.

Paper number 93JD00324.

0148-0227/93/93JD-00324\$05.00 the soil temperature is decreased both directly and by inducing evaporation when melting water penetrates into the soil. The higher amount of soil moisture may contribute to cloud formation and, therefore, have another effect on the air temperature.

The snow cover, however, is undergoing internal changes due to aging processes. The typical "life cycle" of a snow cover is shown in Figure 1. The albedo decreases with increasing grain size, impurity, and wetness of the snow and varies between 0.9 and 0.3 [Dirmhirn, 1953]. The thermal conductivity, being a quadratic function of the snow density, increases from 0.036 to $0.42 \mathrm{~W} /(\mathrm{m} \mathrm{K})$ [Anderson, 1976] when the density is enhanced from 80 to $400 \mathrm{~kg} \mathrm{~m}^{-3}$ as a consequence of the metamorphism processes. This leads to a higher amount of energy being absorbed by the snow surface and being transported into the deeper snow layers with increasing snow age.

Most of the existing numerical models of snow have been developed for the estimation of runoff and cannot be used for climate studies without reservations. Others, with high vertical resolution are primarily orientated to the internal processes of snow. The latter ones make an extensive effort of computing time. An overview comparing snow cover models, which was published by World Meteorological Organization (WMO) [1986], shows the lack of snow cover models meeting the requirements of long-term climate simulations: to be formulated on basic physical principles, to take into account all important processes, and to use an effective numerical scheme.

Several snow models have already been used in calculating surface fluxes in atmospheric circulation models. The shortcoming of the majority of these models, however, is the poor simulation of snow properties: (1) the consideration of the snow cover as a one-layer system with a fixed temperature profile does not allow an accurate simulation of the heat conduction within the snow; (2) aging, water vapor diffusion, and liquid water storage are neglected; (3) constant values 


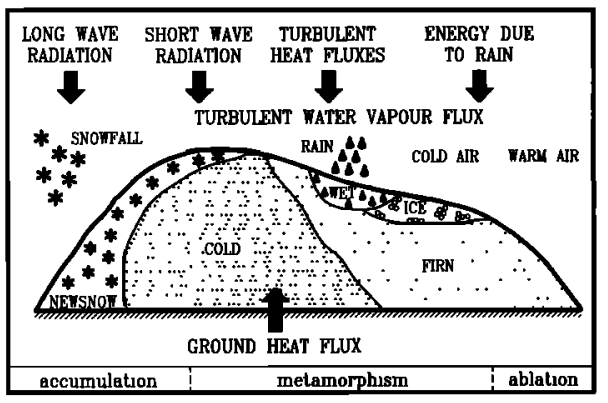

Fig. 1. Accumulation, metamorphism, and ablation of a snow cover.

for the snow density and thermal conductivity are used; and (4) the parameterization of the albedo is simplified.

An important improvement in modeling the snow cover for climate studies was introduced by Verseghy [1991]. Her model considers the internal processes of temperature diffusion, penetration of short wave radiation through the snow, melting, freezing, and aging. In order to treat the processes of snow metamorphism explicitly, the snow density and the snow albedo are assumed to be functions of time. The thermal conductivity changes with snow density following a quadratic parameterization. For a snow depth less than $\mathbf{0 . 1 0}$ $\mathrm{m}$ the snow cover is considered to be patchy. The substantial shortcoming of this model, in our opinion, is that it uses only one snow layer. The energy exchange with both the atmosphere and the soil is not adequately described by an average snow temperature because temperature gradients of about 10 $K$ between the top and the bottom of the snow cover [Wilhelm, 1975] can occur and therefore a vertical resolution of at least two layers is required.

Emphasizing the modification of soil processes by vegetation, Dickinson et al. [1986] developed a simple snow cover model using a time-dependent snow depth, snow density, and snow temperature for 18 types of vegetation. The albedo of snow is separately parameterized for the visible and infrared part of the spectrum taking into account snow age, impurities, and solar zenith angle. The fraction of the grid area covered with snow is calculated as a function of the roughness for both the vegetated and the nonvegetated parts. The snow physics, however, is rather crudely described in their model.

In this investigation a multilayer snow cover model is presented which is based on the mass and energy balances. Using basic physical principles and mostly avoiding tuned parameters, the model includes all important internal processes altering the snow cover. Four snow types (cold snow, wet snow, firn snow, and ice) are distinguished. The complexity and numerical effort of the model makes it suitable for long-term integrations. The forcing terms include only standard meteorological parameters. For the implementation of this one-dimensional snow cover model in a general circulation model, (GCM) parameterizations (analogous to Dickinson et al. [1986]) must be added to relate the snow albedo, the long wave emission, the turbulent heat fluxes, and the mass fluxes, which are representative for a bare soil, to different vegetation and surface types given in modern GCMs for every grid square. The paper is divided as follows: Section 2 describes the physics of the model and we discuss briefly the physical effects on which the parameterizations
TABLE 1. Snow Types Used in the Snow Cover Model

\begin{tabular}{lr}
\hline Snow Type & Density, $\mathrm{kg} \mathrm{m}^{-3}$ \\
\hline Cold/wet snow & $50 \cdots<400$ \\
Firn snow & $400 \cdots<920$ \\
Ice & 920 \\
\hline
\end{tabular}

are based. In section 3 we present some results of our sensitivity studies. Section 4 is devoted to long-term integrations carried out with data sets from Potsdam over a period of six winters. Finally, conclusions of this investigation are given.

\section{Model Physics}

\subsection{General Comments}

The model physics is largely based on parameterizations adapted from Anderson [1976]. Snow is considered as a one-dimensional physical system (vertical coordinate $z$ ) consisting of ice, liquid water, water vapor, and included air. The state is determined by the following variables:

snow depth in $\mathrm{m} \quad h=h(t)$

snow temperature in $\mathrm{K} \quad T=T(z, t)$

dry snow density in $\mathrm{kg} \mathrm{m}^{-3} \quad \rho=\rho(z, t)$

liquid water content in $\mathrm{kg} \mathrm{m}^{-3} \quad w=w(z, t)$

water vapor concentration in $\mathrm{kg} \mathrm{m}^{-3} \quad v=v(z, t)$

The water vapor pressure is assumed to reach the saturation value over ice, so that the water vapor concentration represents a diagnostic variable. It is only a function of the snow temperature and can be estimated by means of the ideal gas equation.

It proved useful to take up an idea of Siemer [1988] to allow the existence of two different snow types. Cold snow is characterized by snow temperatures below the freezing point. Penetrating liquid water freezes immediately. Wet snow, however, has the ability to store liquid water up to a certain threshold value, the retention capacity. For this type of snow a constant temperature of $273.15 \mathrm{~K}$ is demanded.

As a result of the aging processes, snow layers can transform into firn snow and ice. According to the snow density the model distinguishes four types of snow (see Table 1).

Ignoring the lateral fluxes, the energy balance $Q^{*}$ of a snow cover can be expressed as the sum of the following fluxes: (1) short wave radiation balance $Q_{S}^{*}$, which can be calculated from the global radiation $Q_{S}$ and the albedo $\alpha$; (2) long wave radiation balance $Q_{L}^{*} ;$ (3) turbulent heat fluxes $Q_{H}$ (sensible) and $Q_{E S}$ (latent); (4) ground heat flux $Q_{B}$; and (5) the energy input due to rain $Q_{\mathrm{HPR}}$, if the temperature of the liquid precipitation is not equal to the snow temperature.

$$
Q^{*}=Q_{S}^{*}+Q_{L}^{*}+Q_{H}+Q_{E S}+Q_{B}+Q_{\mathrm{HPR}}
$$

The energy fluxes $Q$ depending on the surface snow temperature $T_{S}$ are implicitly formulated because $T_{S}$ reacts instantaneously to anomalies in $Q$.

$$
Q\left(T_{S}^{n+1}\right)=Q\left(T_{S}^{n}\right)+\left.\frac{\partial Q}{\partial T}\right|_{n}\left(T_{S}^{n+1}-T_{S}^{n}\right)
$$


where $Q$ is one of the energy fluxes $Q_{L}^{*}, Q_{H}$, or $Q_{E S}$. An analogous approach is chosen for the heat ground flux and the temperature of the bottom layer.

The mass balance $M^{*}$ is influenced by the intensity of snowfall $M_{\mathrm{PS}}$, rain $M_{\mathrm{PR}}$, the turbulent water vapor flux $M_{V}$, and the runoff $M_{A}$.

$$
M^{*}=M_{\mathrm{PS}}+M_{\mathrm{PR}}+M_{V}-M_{A}
$$

where $M^{*}$ is in $\mathrm{kg} \mathrm{m}^{-2} \mathrm{~s}^{-1}$.

\subsection{Internal Processes}

2.2.1. Heat conduction and water vapor diffusivity. The sensible heat transfer within snow can be described by the Fourier heat conduction equation in the onedimensional form:

$$
c_{S} \rho \frac{\partial T}{\partial t}=\frac{\partial}{\partial z}\left(K(\rho) \frac{\partial}{\partial z} T\right)
$$

where $c_{S}$ is specific heat of snow in $\mathrm{J} /(\mathrm{kg} \mathrm{K})$ and $K$ is effective thermal conductivity of snow. Due to the relatively small variations of $c_{S}$ with snow temperature the specific heat capacity is assigned a constant value of $2105 \mathrm{~J} /(\mathrm{kg} \mathrm{K})$.

The effective thermal conductivity $K$ is a function of the size, shape, and distribution of the ice crystals within the snowpack. It embodies the combined effect of heat conduction through the ice grains and the enclosed air molecules and the radiant energy exchange across the pores. The contribution of liquid water to the heat conduction is neglected. The parameterization of $K$ is taken from Anderson [1976] who proposed a quadratic relation to the snow density in the following form:

$$
K=a+b \rho^{2}
$$

where $a=2 \times 10^{-2} \mathrm{~W} /(\mathrm{m} \mathrm{K})$ and $b=2.5 \times 10^{-6} \mathrm{~W} \mathrm{~m}^{5} /(\mathrm{K}$ kg).

In addition to heat conduction, existing temperature gradients simultaneously cause water vapor diffusion and lead to a mass transfer within the snow cover. The consequence of this process is a growth of cold crystals, the formation of depth hoar, and a release of latent heat due to the sublimation or condensation in the oversaturated colder snow layers. The water vapor flux within the snow cover $M_{v}$ can be expressed by Fick's law of diffusion:

$$
\frac{\partial}{\partial z} M_{V}=-\frac{\partial}{\partial z}\left(D \frac{\partial v}{\partial z}\right)=-\frac{\partial}{\partial z}\left(D \frac{\partial T}{\partial z} \frac{d v}{d T}\right)
$$

where $v$ is the water vapor mass density. The effective diffusion coefficient for water vapor in snow $D$ is related to temperature and pressure. Anderson [1976] assumed for snow a formula similar to the atmospheric approximation

$$
D=D_{0} \frac{p}{p_{0}}\left(\frac{T}{T_{0}}\right)^{n_{D}}
$$

Here $p_{0}=1000 \mathrm{hPa}$ and $T_{0}=273.15 \mathrm{~K}$ symbolize standard values of pressure and temperature. The constant diffusion coefficient $D_{0}$ is set to $9 \times 10^{-5} \mathrm{~m}^{2} / \mathrm{s}$. Anderson [1976] suggested $n_{D}=14$ on the basis of published data.

The latent heat flux $Q_{E}$ results from the water vapor flux
$M_{V}$ multiplied by the latent heat of sublimation $L_{S}$ (for cold snow) or evaporation $L_{V}$ (for wet snow):

$$
Q_{E}=M_{V} L_{S / V}
$$

2.2.2. Processes of melting and freezing. In order to guarantee mass and heat conservation the equations in the melting and freezing scheme are written in mass flux form for the single components of snow.

The melting scheme: The model allows melting processes solely at a snow temperature of $273.15 \mathrm{~K}$. In a first phase the melting water is stored by the snow cover and the water equivalent is conserved. The volume proportion of air to ice mass is maintained. The basic equations have the following form:

$$
\begin{gathered}
\frac{\partial m_{I}}{\partial t}=-\frac{\partial m_{w}}{\partial t} \\
m_{A}^{n+1}=q_{\mathrm{AI}} m_{\mathrm{I}}^{n+1} \frac{\rho_{A}}{\rho_{I}} \quad q_{\mathrm{AI}}=\frac{h_{A}^{n}}{h_{I}^{n}}
\end{gathered}
$$

where $m_{I}$ is the mass of ice, $m_{w}$ stands for the mass of liquid water, and $m_{A}$ is the mass of air enclosed in snow; $h_{A}$ and $h_{I}$ represent the thicknesses of the compact air and ice layer, respectively. If the retention capacity is completely filled up, runoff occurs and the snow depth and water equivalent decrease.

The freezing scheme: Freezing processes appear when liquid water exists in or penetrates into snow with temperatures below $0^{\circ} \mathrm{C}$. Because of the fact that wet snow is able to store liquid water, the amount of released energy $Q$ is given by

$$
Q=\min \left(Q_{1}, Q_{2}\right)
$$

where (1) $Q_{1}$ is the total latent energy of the snow mass

$$
Q_{1}=m_{w} L_{F}
$$

and (2) $Q_{2}$ is the so-called "cold content" of the snow mass

$$
Q_{2}=\rho h c_{S}\left(T_{0}-T^{n}\right)
$$

Cold snow occurs after freezing for $Q_{1}<Q_{2}$. The snow temperature can be estimated by the formula

$$
T^{n+1}=T^{n}+\frac{m_{w} c_{S}\left(T_{0}-T\right)+Q_{1}}{c_{S}\left(m_{l}^{n}+m_{w}^{n}+m_{A}^{n}\right)}
$$

where $c_{S}$ is the specific heat of snow, $T_{0}$ is the melting temperature, and $m_{1}, m_{w}$, and $m_{A}$ are the masses of ice, liquid water, and enclosed air, respectively. If $Q_{1}>Q_{2}$ the former cold snow changes its state. The mass of enclosed air is assumed to be maintained in this scheme, because the freezing processes produce compact ice particles and do not cause further pores.

2.2.3. Short wave radiation. Absorption and scattering of solar energy within the snow cover lead to an exponential decrease of incoming radiation with snow depth. The net short wave radiation $Q_{S}$ at the level $z$ can be expressed as [Dunkle, Bevans, 1956]

$$
Q_{S}(z)=Q_{S}^{*} \exp (-\nu(h-z))
$$


where $Q_{S}^{*}$ is the net short wave radiation at the snow surface, $h$ represents the (total) snow depth and $\nu$ the extinction coefficient of snow.

On the basis of the optical properties of a single particle, Bohren and Barkstrom [1974] derived an approximate solution of the radiation transfer problem. It was found that the extinction coefficient $\nu$, the snow density $\rho$, and the grain size $d$ depend on each other through

$$
\nu=c_{\nu} \sqrt{\frac{\nu_{\text {Ice }}}{d}} \frac{\rho}{\rho_{\text {Ice }}}=C_{\nu} \frac{\rho}{d^{0.5}}
$$

For the coefficient $c_{\nu}$, Bohren and Barkstrom [1974] estimated 0.084. $C_{\nu}$ has a value of $3.8 \times 10^{-3} \mathrm{~m}^{5 / 2} \mathrm{~kg}^{-1}$.

The grain size $d$ is parameterized as a function of snow density following Anderson [1976]:

$$
d=a+b \rho^{4}
$$

with the coefficients $a=1.6 \times 10^{-4} \mathrm{~m}, b=1.1 \times 10^{-13}$ $\mathrm{m}^{13} \mathrm{~kg}^{-4}$.

2.2.4. Liquid water transmission. The porous structure of snow and molecular interactions between water and ice particles enables a snow mass to store liquid water up to a threshold value and to delay the outflow. The calculation of the liquid water content is carried out by using a fixed proportion between the maximum possible mass of stored water $m_{w}^{R}$ and the mass of the given dry snowpack $\rho(h)$, namely, the retention capacity $c^{R}$, which is defined as

$$
c^{R}=\frac{m_{w}^{R}}{\rho h}
$$

This dimensionless parameter can be estimated as a function of density [Anderson, 1976] where $c^{R \min }=0.03, c^{R \max }=$ $0.10, \rho_{e}=200 \mathrm{~kg} \mathrm{~m}^{-3}$ :

$$
c^{R}= \begin{cases}c^{R \min } & \text { if } \rho \geqq \rho_{e} \\ c^{R \min }+\left(c^{R \max }-c^{R \min }\right) \frac{\rho_{e}-\rho}{\rho_{e}}, & \text { if } \rho<\rho_{e}\end{cases}
$$

2.2.5. Metamorphism of snow. The term metamorphism covers all temporal changes in the snow crystal structure. Sommerfeld and La Chapelle [1970] classified the processes and divided them into three basic types: (1) the equitemperature metamorphism (destructive metamorphism, settling), the modification of snow due to water vapor diffusion which leads to a decrease in the surface energy; (2) the temperature-gradient metamorphism (constructive metamorphism), the transport of water vapor along a strong thermal gradient; (3) firnification, which consists of the melt-freeze metamorphism, growth of grains due to passing melt-freeze cycles, and the pressure metamorphism (compaction), the compaction on level $z$ caused by the overlying snow mass.

The effects of constructive and melt-freeze metamorphism are considered in sections 2.2 .1 and 2.2.2. Compaction and settling are parameterized by empirical functions of the weight of the snowpack and the snow temperature which are taken from Anderson [1976].

Changes in density due to compaction can be estimated by the ratio of the weight of the overlying snow to a viscosity coefficient $\eta_{c}$ which represents the resistance of the snowpack to a given pressure.

$$
\frac{1}{\rho(z, t)} \frac{\partial \rho(z, t)}{\partial t}=\frac{1}{\eta_{c}} g \int_{z}^{h(t)} \rho\left(z^{\prime}, t\right) d z^{\prime}
$$

where $g=9.81 \mathrm{~m} \mathrm{~s}^{-2}$ is the gravity constant.

Observations [Kojima, 1967] show that an increase in snow density $\rho$ is accompanied with an exponential enhancement of the viscosity $\eta_{c}$.

$$
\eta_{c}=\eta_{t} \exp \left(a_{c} \rho\right) \text { where } a_{c}=2.1 \times 10^{-2} \mathrm{~m}^{3} \mathrm{~kg}^{-1}
$$

where the coefficient $\eta_{t}$ represents the viscosity at a temperature T. Mellor [1964] further suggested a temperature dependence of the viscosity which can be expressed also exponentially:

$$
\eta_{t}=\eta_{0} \exp \left[b_{c}\left(T_{0}-T\right)\right]
$$

where $b_{c}=8.1 \times 10^{-2} \mathrm{~K}^{-1}$ and $T_{0}=273.15 \mathrm{~K}$ and $\eta_{0}=$ $3.7 \cdot 10^{7} \mathrm{~Pa} s$ is the viscosity at $0^{\circ} \mathrm{C}$ and $\rho=0 \mathrm{~kg} \mathrm{~m}^{-3}$.

The influence of the settling which leads to a decrease in surface-free energy is primarily important in new snow layers. Because of the lack of a quantitative relation, Anderson [1976] formulates an approach on the basis of reasonable physical understanding. For the estimation of the settling rate he proposed a function of temperature (snow tends to settle more rapidly at higher temperatures) and snow density (the processes wear off with age and increasing grain size).

$$
\begin{aligned}
\frac{1}{\rho(z, t)} \frac{\partial \rho(z, t)}{\partial t}=a \exp \left[-b\left(T_{0}-T(z, t)\right)\right. & \\
& \left.-c\left(\rho(z, t)-\rho_{d}\right)\right]
\end{aligned}
$$

The coefficients $a$ and $\rho_{d}$ are determined on the basis of observations. Gunn [1965] reported that newly fallen snow with snow densities between $50 \mathrm{~kg} \mathrm{~m}^{-3}$ and $150 \mathrm{~kg} \mathrm{~m}^{-3}$ settles at a density-independent rate of about $1 \%$ per hour. Yen [1969] points out that the settling process is of minor importance for densities greater than $250 \mathrm{~kg} \mathrm{~m}^{-3}$. Therefore the coefficient $a$ is assigned a value of $2.8 \times 10^{-6} \mathrm{~s}^{-1}$ and $\rho_{d}$ is set $150 \mathrm{~kg} \mathrm{~m}^{-3}$. The coefficients

$b=4 \times 10^{-2} \mathrm{~K}^{-1}$ and $c$

$$
= \begin{cases}0.0 & \text { if } \rho<\rho_{d} \\ 4.6 \times 10^{2} \mathrm{~m}^{3} \mathrm{~kg}^{-1} & \text { if } \rho \geqq \rho_{d}\end{cases}
$$

were estimated by calibration [Anderson, 1976].

2.2.6. Mass balance and internal energy. In each time step the model predicts the changes in snow mass and internal energy of the snow cover and compares these values with the sum of exchange fluxes to the atmosphere and the soil. Because of the conservative character of the chosen flux form of mass and energy the differences show the accuracy of the solution technique. The balances can be expressed as

$$
\begin{aligned}
M\left(t_{1}\right)-M\left(t_{0}\right)= & \int_{0}^{h\left(t_{1}\right)}\left[\rho\left(z, t_{1}\right)+w\left(z, t_{1}\right)\right) d z \\
& -\int_{0}^{h\left(t_{0}\right)}\left(\rho\left(z, t_{0}\right)+w\left(z, t_{0}\right)\right] d z
\end{aligned}
$$


TABLE 2. Clear Sky Albedo for Snow Covers [Gray and Landine, 1987]

\begin{tabular}{ll}
\hline Decrease Rate & \multicolumn{1}{c}{ Validity Interval } \\
\hline $\mathbf{- 0 . 0 0 6 1 / d a y}$ & in premelt periods \\
$-0.071 /$ day & in melting periods, for depth $<0.25 \mathrm{~m}$ \\
$-0.015 /$ day & in melting periods, for depth $\geqq 0.25 \mathrm{~m}$ \\
$\mathbf{- 0 . 1 9 6 / d a y}$ & in postmelt periods \\
\hline
\end{tabular}

$$
\begin{aligned}
E\left(t_{1}\right)-E\left(t_{0}\right)= & \int_{0}^{h\left(t_{1}\right)}\left[\rho\left(z, t_{1}\right) T\left(z, t_{1}\right) c_{S}\right. \\
& \left.+w\left(z, t_{1}\right) T_{0}\left(z, t_{1}\right) c^{*}\right] d z \\
& -\int_{0}^{h\left(t_{0}\right)}\left[\rho\left(z, t_{0}\right) T\left(z, t_{0}\right) c_{S}\right. \\
& \left.+w\left(z, t_{0}\right) T_{0}\left(z, t_{0}\right) c^{*}\right] d z \\
c^{*}= & c_{E}+L_{F} / T_{0}
\end{aligned}
$$

where $c_{E}=1900 \mathrm{~J} /(\mathrm{kg} \mathrm{K})$ is the heat capacity of ice, $T_{0}=$ $273.15 \mathrm{~K}$ is the melting temperature, and $L_{F}=0.334 \mathrm{~J} / \mathrm{kg}$ is the latent heat of fusion.

\subsection{Boundary Conditions}

2.3.1. Short wave balance at snow cover surface. The short wave radiation balance $Q_{S}^{*}$ depends on the global radiation $Q_{s}$ and the albedo $\alpha$, the ratio of reflected to incoming solar radiation.

$$
Q_{S}^{*}=(1-\alpha) Q_{S}
$$

The insolation $Q_{S}$ is given as a measurement in the input data set. Otherwise it can be estimated by a short wave radiation model, e.g., that of Siemer [1988], on the basis of astronomical and geographical data, horizon screening data, and atmospheric extinction.

The snow albedo $\alpha$ shows a high variability. Its value ranges widely between 0.9 for pure and dry fresh snow and 0.3 for snow at the end of the melting phase [Dirmhirn, 1953]. Although there is also a spectral dependence [Wiscombe and Warren, 1980], as a first step we confine the albedo to integral values. The integral reflectivity of snow is a function of a large number of parameters. The influencing factors can be summarized into the following three groups: (1) the internal structure of snow cover (grain size and shape, wetness, purity, surface roughness); (2) the elevation angle of the Sun and the proportion of diffuse to direct solar radiation; and (3) the radiation properties of the underlying soil up to a threshold value of snow depth $(25 \mathrm{~cm})$.

The snow cover model starts with the determination of the clear sky albedo, which represents the albedo for cloudless sky and the Sun's zenith. The parameterization used (Table 2) is taken from Gray and Landine [1987]. It depicts a linear decrease in the snow albedo with time which occurs as the result of the metamorphism processes. The relations are derived from point observations of the incoming and reflected global radiation from February 1 to the end of ablation and originally refers to prairie snow. Different coefficients are given for the premelt, melting, and postmelt periods.
Influence of clouds and the elevation angle of Sun on the albedo: A cloud cover changes the proportion of diffuse to direct solar radiation. Multiple reflections between snow surface and cloud bottom increase the ratio of short wave to long wave radiation because radiation of wavelengths greater than the visible part of the spectrum are absorbed by clouds and snow to a much greater extend than shorter wavelengths [Wiscombe and Warren, 1980]. The deviations of albedo under conditions of overcast sky from that of clear sky are in the range of 7 to 20\% [Petzold, 1977; Choudhury and Chang, 1981; Dirmhirn and Eaton, 1975].

Observations [Liljequist, 1956; Dirmhirn and Eaton, 1975] as well as calculations carried out with sophisticated albedo models [Wiscombe and Warren, 1980] show an increase in the integral and the spectral albedo at all wave lengths as the zenith angle $\Theta$ increases. Because the albedo only depends on the cosine of the zenith angle, it rapidly changes with $\Theta$ at large values of $\Theta$ and it is negligible for $\Theta<50^{\circ}$ [Petzold, 1977]. Under cloudless conditions the change of the integral albedo is in the range of 5 to $10 \%$ between elevation of Sun of $10^{\circ}$ to $40^{\circ}$ [Choudhury and Chang, 1981].

In our model the influence of clouds and the elevation angle of the Sun on the albedo is introduced by applying a formula from Siemer [1988] in which he suggested

$$
\alpha\left(\alpha_{0}, N, \Theta\right)=\alpha_{0}+\alpha_{0}^{n_{a}}\left(1-\alpha_{0}\right) \phi(N, \Theta)
$$

where $\alpha$ is the integral albedo, $\alpha_{0}$ represents the clear sky albedo, and $N$ and $\Theta$ are the cloud amount and the zenith angle of the Sun, respectively. The exponent $n_{a}$ is set to 3 .

The function $\phi(N, \Theta)$ is assumed as the weighted sum of the two monotonously increasing functions $\phi_{1}(N)$ and $\phi_{2}(\Theta)$ and their product $\phi_{1}(N) \phi_{2}(\Theta)$ :

$$
\phi(N, \Theta)=a \phi_{1}(N)+b \phi_{2}(\Theta)+c \phi_{1}(N) \phi_{2}(\Theta)
$$

On the basis of data for four polar stations quoted by Petzold [1977], Siemer [1988] suggested a quadratic relationship between the albedo $\alpha$ and the amount of clouds $N: \phi_{1}(N)=N^{2}$.

Due to the facts that (1) the influence of cloud cover is stronger for large zenith angles

$$
\left|\frac{\partial \alpha}{\partial N}\right|_{\Theta<60^{\circ}}>\left|\frac{\partial \alpha}{\partial N}\right|_{\Theta \geqq 60^{\circ}},
$$

(2) the albedo changes less with $\Theta$ for smaller zenith angle $\Theta$

$$
\alpha \cong \alpha_{0} \quad \text { if } \Theta \leqq 60^{\circ},
$$

(3) the albedo increases monotonously with increasing zenith angle

$$
\frac{\partial \alpha}{\partial \Theta}>0 \quad \text { if } \Theta>60^{\circ},
$$

the dependence of albedo on the zenith angle of the Sun $\Theta$ can be formulated as an exponential function of the cosine of $\Theta: \phi_{2}(\Theta)=\exp \left[1-\left(1-\cos (\Theta)^{2}\right)\right]$. Siemer [1988] estimated the coefficients $a=1, b=1$, and $c=-1.3$ using the results of Choudhury and Chang [1981].

2.3.2. Long wave emission and infrared back radiation. Assuming that the snow cover can be treated as a blackbody in the infrared part of the spectrum [Anderson, 1976; Wiscombe and Warren, 1980], the long wave radiation balance $Q_{L}^{*}$ can be written in the following form:

$$
Q_{L}^{*} \approx-\sigma T_{S}^{4}+\left[\varepsilon_{A}(N=0) \sigma T_{A}^{4}+Q_{L C}\right]
$$


where $\sigma=5.67 \times 10^{-8} \mathrm{~W} /\left(\mathrm{m}^{2} \mathrm{~K}^{4}\right)$ is the Stefan-Boltzmann constant. $T_{S}$ and $T_{A}$ stand for the surface snow temperature and for the air temperature, respectively. $N$ is the total amount of clouds in fractions $[N \in(0,1)]$.

The emissivity of air $\varepsilon_{A}$ can be estimated for cloudless conditions by a function of water vapor pressure and the air temperature [Idso, 1981]:

$$
\varepsilon_{A}(N=0)=a+b e_{A} \exp \left(\frac{c}{T_{A}}\right)
$$

where $a=0.70, b=5.95 \times 10^{-7} \mathrm{~Pa}^{-1}$, and $c=1500 \mathrm{~K}$.

$Q_{\mathrm{LC}}$ is the incoming long wave radiation at the surface which is emitted by clouds. This energy flux is a function of the properties of the existing clouds (the temperature at the bottom of the clouds $T_{c}$ and their emissivity $\varepsilon_{c}$ ), the transmissivity of atmosphere $t_{A}^{8-14}$ in the water vapor window 8-14 $\mu \mathrm{m}$ and the total amount of clouds $N$ [Kimball et al., 1982].

$$
Q_{\mathrm{LC}}=t_{A}^{8-14} N f_{c}^{8-14} \varepsilon_{c} \sigma T_{c}^{4}
$$

$f_{c}^{8-14}$ guarantees that only the amount of energy in the spectral interval 8-14 $\mu \mathrm{m}$ is considered. It can be determined by a formula taken from Kimball et al. [1982]:

$$
f_{c}^{8-14}=a+b T_{c}+c T_{c}^{2}
$$

where $a=-0.6732, b=0.6240 \times 10^{-2} \mathrm{~K}^{-1}$, and $c=$ $-0.9140 \times 10^{-5} \mathrm{~K}^{-2}$.

The transmissivity of the atmosphere in the water vapor window 8-14 $\mu \mathrm{m} t_{A}^{8-14}$ can be gauged by calculating the emissivity of atmosphere $\varepsilon_{A}^{8-14}$ in the same part of the spectrum and including a correction for different heights above sea level [Idso, 1981]:

$$
\begin{gathered}
t_{A}^{8-14}=1-\varepsilon_{A}^{8-14} \\
\varepsilon_{A}^{8-14}=\varepsilon_{8-14, z}\left(1.4-0.4 \varepsilon_{8-14, z}\right) \\
\varepsilon_{8-14, z}=a+b e_{A}^{2} \exp \left(\frac{c}{T_{A}}\right) \exp \left(\frac{z}{H}\right)
\end{gathered}
$$

where $a=0.24, b=2.98 \times 10^{-6} \mathrm{~Pa}^{-2}$, and $c=3000 ; e_{A}$ and $T_{A}$ represent the water vapor pressure and the temperature of the air, respectively. $H=8000 \mathrm{~m}$ is the height of the homogeneous atmosphere. The emissivity of clouds $\varepsilon_{c}$ is assumed to be 1 for low clouds, 0.75 for mean clouds, and 0.50 for high clouds [Siemer, 1988].

The cloud base temperature of cumulus clouds is estimated by the approach

$$
T_{c}=T_{A}-\gamma_{d}\left(z_{c}-z\right)
$$

where $\gamma_{d}=0.01 \mathrm{~K} / \mathrm{m}$ and $z_{c}-z$ is the height of the clouds above ground.

In the case of cumulus condensation the height of the clouds can be calculated as a function of the difference between the air temperature $T_{A}$ and the dew point temperature $T_{\mathrm{dA}}$.

$$
z_{c}-z=123\left(T_{A}-T_{\mathrm{dA}}\right) .
$$

As a first approximation we use this relation for all types of clouds.

2.3.3. Turbulent heat fluxes. The turbulent heat fluxes
$Q_{H}$ and $Q_{E}$ are important components for the interaction with the atmosphere, because they are functions of the surface temperature $T_{S}$ which again depends on the input energy fluxes itself.

According to the turbulent theory, bulk equations with empirical wind functions are used for the estimation of the water vapor flux $M_{V}$ and the sensible heat flux $Q_{H}$. The coefficients are taken from Anderson [1976] who carried out comprehensive investigations in this field and finally proposed the following relations:

$$
\begin{gathered}
M_{V}=f(u)\left(e_{A}-e_{S}\right), \quad Q_{E}=L_{\mathrm{S} / \mathrm{V}} M_{V} \\
Q_{H}=\frac{p c_{P}}{\varepsilon} f(u)\left(T_{A}-T_{S}\right) \\
\left.f(u)=a+b u, \quad a=0, \quad b=25 \times 10^{-9} \mathrm{~kg} /(\mathrm{Pa} \mathrm{m})^{3}\right),
\end{gathered}
$$

where $u$ stands for the wind speed at $10 \mathrm{~m}$ height; $e_{A}-e_{S}$ and $T_{A}-T_{S}$ are the differences in vapor pressure and temperature between the air and the snow surface, respectively; $p$ represents the surface air pressure; and $c_{p}$ is the specific heat capacity of air. The proportion of the gas constant of dry air to that of water vapor $\varepsilon$ has a value of about 0.622 . For cold snow, $L_{\mathrm{S} / \mathrm{V}}$ is given by the latent heat of sublimation $L_{S}=2.834 \times 10^{6} \mathrm{~J} \mathrm{~kg}^{-1}$. For wet snow, $L_{\mathrm{S} / \mathrm{V}}$ equals the latent heat of evaporation $\left(2.5 \times 10^{6} \mathrm{~J} \mathrm{~kg}^{-1}\right)$.

2.3.4. Ground heat flux. By comparison with the short and long wave radiation fluxes the ground heat flux is negligible. Nevertheless, it has the ability to thaw a soil under a snow cover [Bauer et al., 1983].

The ground heat flux through the soil surface $Q_{B}$ can be estimated by means of the heat conduction equation

$$
Q_{B}=-\lambda \frac{\partial T_{B}}{\partial z}
$$

$T_{B}$ is the soil temperature in degrees Kelvin. The thermal heat conductivity of soil $(\lambda)$ which varies widely with water content and soil type is set $0.3 \mathrm{~W} /(\mathrm{m} \mathrm{K})$.

2.3.5. Precipitation. The precipitation has an effect on both the mass budget and the energy balance. The temperature of precipitation $T_{P}$ is assumed to equal the wet bulb temperature of air with a lower limit of $0^{\circ} \mathrm{C}$ for rain. For the initial profiles the air temperature is used as an approximation of the snow temperature.

Different parameterizations whether precipitation occurs as snow or rain are overviewed by Rohrer [1989]. In our simulations the choice of the aggregational state was made on the basis of near-surface air temperature data given for Davos (Switzerland) in the work of Wilhelm [1975]. For air temperatures between $-1^{\circ} \mathrm{C}$ and $4^{\circ} \mathrm{C}$ we introduce a mixed zone in which snow and rain coexist (Table 3).

If the precipitation is interpreted as rain, the retention capacity and the trapped liquid water $M_{\text {PRS }}$ are calculated. For temperatures of precipitation $T_{P}$ greater than the melting temperature $T_{0}$ the liquid water increase is connected with a heat flux $Q_{\mathrm{HPR}}$ :

$$
Q_{\mathrm{HPR}}=c_{w}\left(T_{P}-T_{0}\right) M_{\mathrm{PRS}}
$$

In this equation, $c_{w}=4187 \mathrm{~J} /(\mathrm{kg} \mathrm{K})$ is the heat capacity of water.

In the case of snowfall a new-snow layer with a snow 
TABLE 3. Aggregational State of Precipitation as a Function of Air Temperature in Percent [Wilhelm, 1975]

\begin{tabular}{lrrrrrr}
\hline & \multicolumn{5}{c}{ Air Temperature, ${ }^{\circ} \mathrm{C}$} \\
\cline { 2 - 7 } & -1 & 0 & 1 & 2 & 3 & 4 \\
\hline Snowfall & 98 & 93 & 50 & 30 & 8 & 1 \\
Snowfall/rain & 1 & 4 & 23 & 15 & 7 & 0 \\
Rain & 1 & 3 & 27 & 55 & 85 & 99 \\
\hline
\end{tabular}

density of $80 \mathrm{~kg} \mathrm{~m}^{-3}$ for air temperatures greater than $-15^{\circ} \mathrm{C}$ and $50 \mathrm{~kg} \mathrm{~m}^{-3}$ otherwise is added. The albedo is increased by 0.1 per $1-\mathrm{cm}$ depth of new snow until it reaches the value of 0.85 [Gray and Landine, 1987]. If the depth of new snow does not exceed $0.5 \mathrm{~cm}$, no separate layer is opened. The uppermost layer is extended.

\subsection{Solution Technique}

The snow cover model is numerically formulated as a layered system in finite differences. The integration time step is 2 hours. The required data set consists of (1) atmospheric data: air and dew point temperature near the surface, surface air pressure, wind speed at $10 \mathrm{~m}$, total amount of clouds and type of cloud, and precipitation; (2) soil temperature; (3) global radiation; (4) geographical data: slope inclination and direction, horizon screening data, and longitude, latitude, and height above sea level.

The initialization of the snow cover model is carried out by snowfall which brings about a snow depth of at least $1 \mathrm{~mm}$. The snow cover is built up of two equivalent layers. The value of $1 \mathrm{~mm}$ is also used for the minimum snow depth of the model. At the end of each time step, two neighboring layers are connected if (1) both are cold layers and the temperature gradient is less than $3 \mathrm{~K}$ and (2) they are two firn snow or ice layers. This procedure avoids having a great number of thin layers with similar state parameters. For these considerations the surface and bottom layer of snow cover are excluded.

Heat conduction: In a layered snow cover the heat conduction equation (4) represents a linear equation system for the coordinate $z$ :

$$
\begin{aligned}
\rho_{i} c_{S} \frac{\partial T_{i}}{\partial t}=\frac{1}{h_{i}}\left(2 K_{i, l}-1 \frac{T_{i-1}-T_{i}}{h_{i-1}}+h_{i}\right. & \\
& \left.+2 K_{i, i+1} \frac{T_{i+1}-T_{i}}{h_{i+1}+h_{i}}\right)+F_{i}
\end{aligned}
$$

where $i$ is the layer index for the middle layers with $0<i<$ $N_{\text {LAYERS }}$ where $N_{\text {LAYERS }}$ is the total number of snow layers; $h_{i}, \rho_{i}$, and $T_{i}$ represent the snow depth, the snow density, and the snow temperature of the $i$ th layer, respectively; $t$ is the integration time. The specific heat of snow is assigned a constant value of $2105 \mathrm{~J} /(\mathrm{kg} \mathrm{K})$.

The effective thermal conductivity coefficients $K_{i, i-1}$ and $K_{i, i+1}$ describe the temperature diffusion between the layers $i$ and $i-1$ and the layers $i$ and $i+1$, respectively. The coefficients are symmetric, that means $K_{i, i-1}=K_{i-1, i}$ and $K_{i, i+1}=K_{i+1, i}$. They can be calculated as the weighted mean of the coefficients of the neighboring layers $K_{i}$ and $K_{i-1}\left(K_{i+1}\right)$. This formulation for $K$ is correct for the applied numerical scheme [Richtmyer and Morton, 1967].

$$
K_{i, i-1}=\frac{K_{i} h_{i}+K_{i-1} h_{i-1}}{h_{i}+h_{i-1}} \quad K_{i, i+1}=\frac{K_{i} h_{t}+K_{i+1} h_{i+1}}{h_{i}+h_{i+1}}
$$

The source term $F_{i}$ is the sum of the absorbed short wave radiation flux $Q_{\mathrm{R}_{1}}$, the energy input due to rain $Q_{\mathrm{HPRi}}$, and the latent heat flux $Q_{\mathrm{Ei}}$ which are estimated for each layer.

As boundary conditions we use the heat conduction equation in a similar form. The energy fluxes to the atmosphere and to the soil are introduced implicitly. The long wave radiation balance and the turbulent heat fluxes act as further forcing components in the surface layer. In the bottom layer of the snow cover we additionally consider the ground heat flux.

In order to guarantee numerical stability even for extremely thin layers the equation system is written Euler backward. For its solution we apply the direct technique of Richtmyer and Morton [1967] which provides the new temperature values in one step.

\section{Sensitivity Studies}

\subsection{General Model Behavior}

We started the sensitivity tests with an analysis of the general physical behavior of the snow cover model. For this purpose we carried out simulations under different atmospheric conditions. It proved useful to investigate the following test period of 15.5 days (Table 4). Additionally, we focused our attention on the model reactions at the time of changing boundary conditions, e.g., the sudden temperature increase of $10 \mathrm{~K}$.

The wind speed is set to $2 \mathrm{~m} \mathrm{~s}^{-1}$, the surface air pressure equals the standard pressure $(1013.25 \mathrm{hPa})$, and the soil temperature is $273.3 \mathrm{~K}$. The dew point temperature differs

\begin{tabular}{|c|c|c|c|}
\hline $\begin{array}{c}\text { Time Interval, } \\
\text { Day }\end{array}$ & $\begin{array}{c}\text { Air } \\
\text { Temperature }\end{array}$ & $\begin{array}{l}\text { Precipitation } \\
\text { per Time Step }\end{array}$ & Comment \\
\hline $1-3$ & $272.15 \mathrm{~K},-1^{\circ} \mathrm{C}$ & $2 \mathrm{~mm}$ & $\begin{array}{l}\text { typical for longer snowfall/accumulation } \\
\text { period }\end{array}$ \\
\hline $3-5.5$ & $274.15 \mathrm{~K},+1^{\circ} \mathrm{C}$ & $2 \mathrm{~mm}$ & $\begin{array}{l}\text { typical for precipitation and temperatures } \\
\text { slightly above } 0^{\circ} \mathrm{C}\end{array}$ \\
\hline $5.5-10$ & $267.15 \mathrm{~K},-6^{\circ} \mathrm{C}$ & none & $\begin{array}{l}\text { typical for dry and relatively low snow } \\
\text { and air temperatures }\end{array}$ \\
\hline $10-15.5$ & $277.15 \mathrm{~K},+4^{\circ} \mathrm{C}$ & none & typical for melting processes/ablation \\
\hline
\end{tabular}
from air temperature by $-0.5 \mathrm{~K}$. The global radiation (Figure

TABLE 4. Input Data Set Used for the Simulation of a Test Period of 15.5 Days 


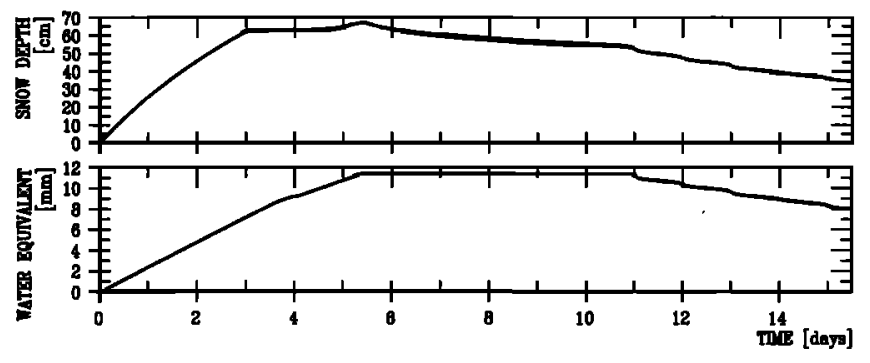

Fig. 2. Simulated snow depth and water equivalent during the test period.

4) was taken from the meteorological station Potsdam $\left(52^{\circ} \mathrm{N}\right.$, $\left.13^{\circ} \mathrm{E}\right)$. The values used are typical for central Europe and the autumn season.

Results: The given atmospheric parameters result in a continuous increase in snow depth and water equivalent from day 0 to day 5.5 (Figure 2). The nonlinear growth of the snow depth is caused by the aging processes and is realistically reproduced. According to the "snow-rain criterion" used, the model simulates a reduced accumulation rate for day 3 to day 5.5. The following cold period is characterized by a decrease in snow depth due to the work of compaction and settling and a constant water equivalent. In the melting phase both snow depth and water equivalent decline in value. The time delay in outflow at day 10 is the consequence of the ability of the snow cover to store liquid water. In all these intervals the snow cover occurs in two or three layers.

The simulated snow surface temperature (Figure 3) has a constant value of $273.15 \mathrm{~K}$ during the warm spell of raining and the melting period. Under the colder conditions the temperature drops below the freezing point. It undergoes a daily cycle which is stimulated by the global radiation. A comparison of the snow surface temperatures of days 1 and 2 shows the sensitivity of the model to variations in the global radiation.

The energy fluxes to the atmosphere and to the soil (Figure 4) are of the expected magnitude. The long wave radiation balance varies between $-40 \mathrm{~W} \mathrm{~m}^{-2}$ and $10 \mathrm{~W} \mathrm{~m} \mathrm{~m}^{-2}$. The turbulent heat fluxes have values between $-12 \mathrm{~W} \mathrm{~m}^{-2}$ and $12 \mathrm{~W} \mathrm{~m}^{-2}$. The ground heat flux is between 0 and $30 \mathrm{~W} \mathrm{~m}^{-2}$. Fluxes that depend on the snow surface temperature and the ground heat flux show a daily cycle. After the air temperature decrease at day 5.5 the long wave radiation balance and the turbulent heat fluxes decrease rapidly. This is caused by

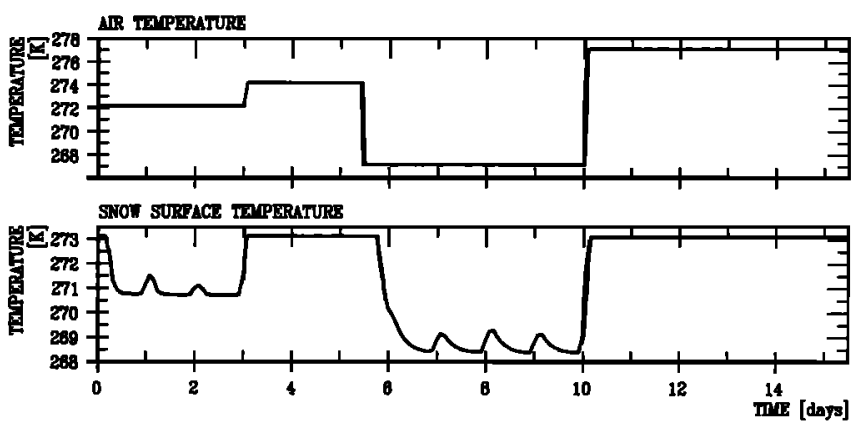

Fig. 3. Air temperature and simulated snow temperature during the test period.
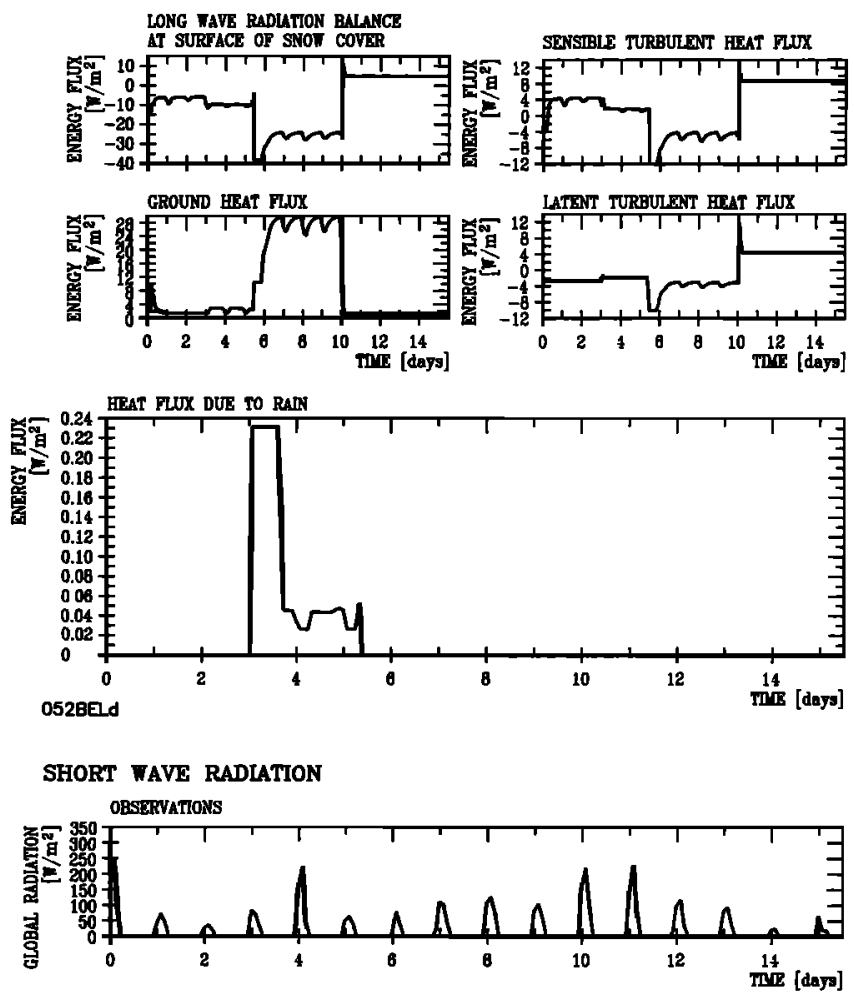

Fig. 4. Simulated energy fluxes during the test period.

the existing large temperature gradient between the snow surface and the air. The same, but with opposite sign, holds for the change of the boundary conditions after day 10 . The heat input due to rain decreases from $0.24 \mathrm{~W} \mathrm{~m}^{-2}$ to about $0.03 \mathrm{~W} \mathrm{~m}^{-2}$.

The heavy snowfall of the first days brings about a clear sky albedo of 0.75 up to day 5 which is equal to that of new snow (see Figure 5). In the third time interval the albedo decreases at a rate of $-0.0061 / d a y$. During the melting period the albedo decays more rapidly (by $-0.071 /$ day). The total decrease from 0.70 to 0.35 in 4 days is typical of the change in albedo during melting periods. The albedo of snow depends on the solar elevation (see section 2.3.1). Because of generally small angles of elevation of the Sun in our simulations a daily cycle is pronounced in the albedo with higher values in the morning and evening hours.

The internal profiles of snow temperature, liquid water

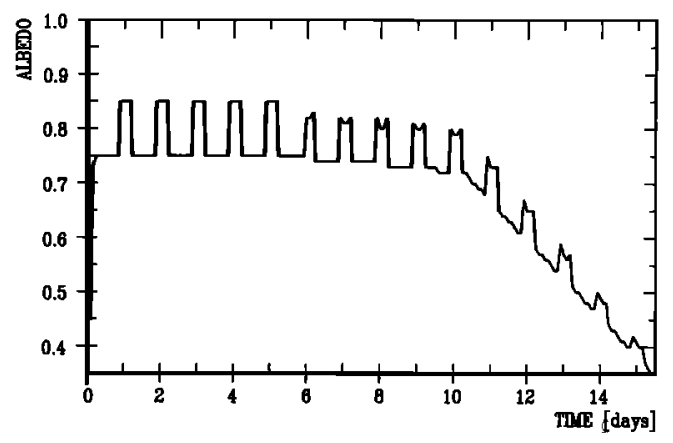

Fig. 5. Simulated snow albedo during the test period 15.5 days using the linear parameterization from Gray and Landine [1987]. 
content, and density are shown in Figure 6. The top curve describes the development of the snow temperature. Whereas during the cold periods the daily cycle of snow temperature is present with a vertical weakening down to the bottom layer (not visible in Figure 6 due to the resolution); during the two warmer periods the temperature is constant and equals the melting point $(273.15 \mathrm{~K})$. The middle figure shows the liquid water content. The liquid water content increases, due to rain or melting processes, during the second and fourth intervals and reaches the retention capacity after 1 day. The snow density profile (bottom figure) indicates the typical increase with time which is caused by aging processes.

In a further simulation (not shown) the precipitation per time step was reduced to $0.8 \mathrm{~mm}$. The consequences were a decrease in snow depth to a third of its former value and an increase in the daily amplitude of the snow surface temperature by $0.5 \mathrm{~K}$. The long wave radiation balance and the turbulent heat fluxes show a weaker sensitivity to the unsteadiness of the air temperature at day 5.5 and day 10 (the absolute value decreases by about $4 \mathrm{~W} \mathrm{~m}^{-2}$ ). This is caused by different energy amounts which are necessary to heat or cool two snow covers with different depth by the same temperature difference. Consequently, in comparison with shallow snow cover, a deeper snowpack has a stronger sensitivity to sudden changes in the air temperature.

In order to investigate the model behavior at low temperatures the air temperature in all four time intervals was decreased by $10 \mathrm{~K}$. The results of that test simulation are qualitatively the same as those described above.
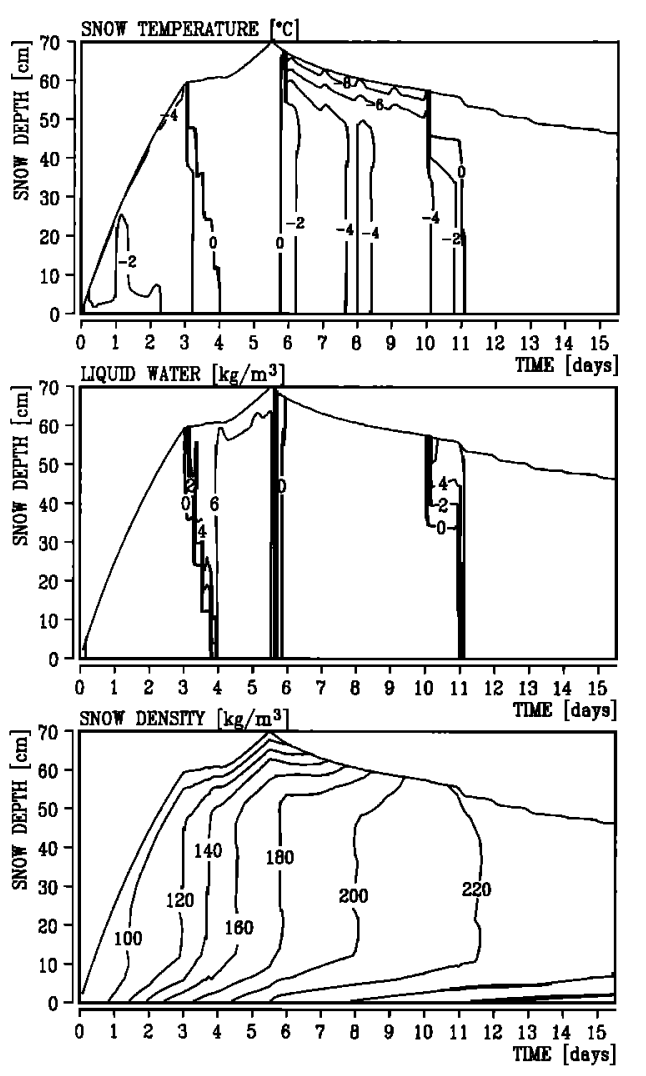

Fig. 6. Internal profiles of snow temperature, liquid water content, and snow density during the test period. a) wet bulb temperature of $1^{\circ} \mathrm{C}$ (ANDERSON, 1976)
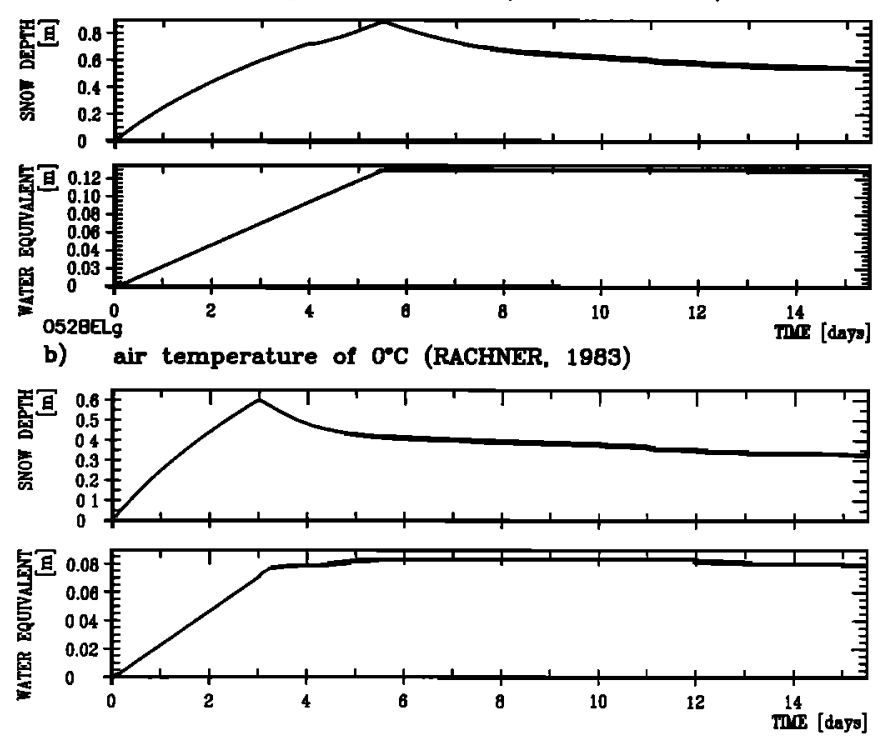

Fig. 7. Simulated snow depth and water equivalent during the test period applying different criteria for the distinction of snowfall and rain.

\subsection{Snow-Rain Criterion}

The sensitivity of the model to the implemented snow-rain criterion of the fallen precipitation was tested by means of two data sets: (1) data from the test period described in section 3.1 and (2) observations from Potsdam (time interval, November 27 to December 12, 1980). The determination of the aggregational state was carried out using (1) threshold values of the wet bulb temperature of the air $\left(1^{\circ} \mathrm{C}\right.$, Anderson [1976] and $2^{\circ} \mathrm{C}$, Siemer [1988]); (2) a threshold value of the air temperature $\left(0^{\circ} \mathrm{C}\right.$, Rachner [1983]); and (3) a distribution of the relative abundance of snow and rain as a function of the air temperature given by Wilhelm [1975].

The simulations point out a great dissimilarity in the accumulated snow depths and water equivalent. The application of the wet bulb temperature as suggested by Anderson [1976] results in a snow depth of $90 \mathrm{~cm}(13 \mathrm{~mm}$ water equivalent) (Figure 7). Use of the air temperature of $0^{\circ} \mathrm{C}$ indicates about $60 \mathrm{~cm}$ and $9 \mathrm{~mm}$ water equivalent. The third criterion was applied in the standard version. It results in a snow depth of $69 \mathrm{~cm}$ and a water equivalent of $11.7 \mathrm{~mm}$ (see Figure 2). Analogous to section 3.1 these modeled snow depths and masses are accompanied by different daily amplitudes and absolute values of the snow surface temperatures (changing by $1 \mathrm{~K}$ and $3 \mathrm{~K}$, respectively). The same occurred for the energy fluxes. Thus the snow-rain criterion influences not only the snow parameter but also the energy transfer to the atmosphere.

The further simulations with the second data set were carried out with the criteria which were suggested by Siemer [1988] and Rachner [1983]. The contrast between the computed and the observed values again reflects the strong sensitivity of the model (Figure 8).

\subsection{Global Radiation and Albedo}

In order to estimate the influence of the short wave radiation balance on the development of a snow cover, a 
a) wet bulb temperature of $20 \mathrm{C}$ (Siemer, 1988)

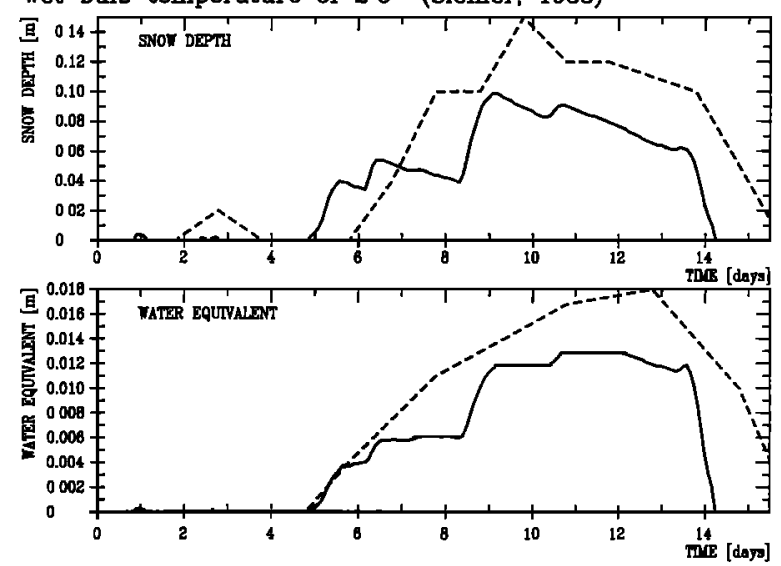

b) air temperature of $0^{\circ} \mathrm{C}$ (Rachner, 1983)
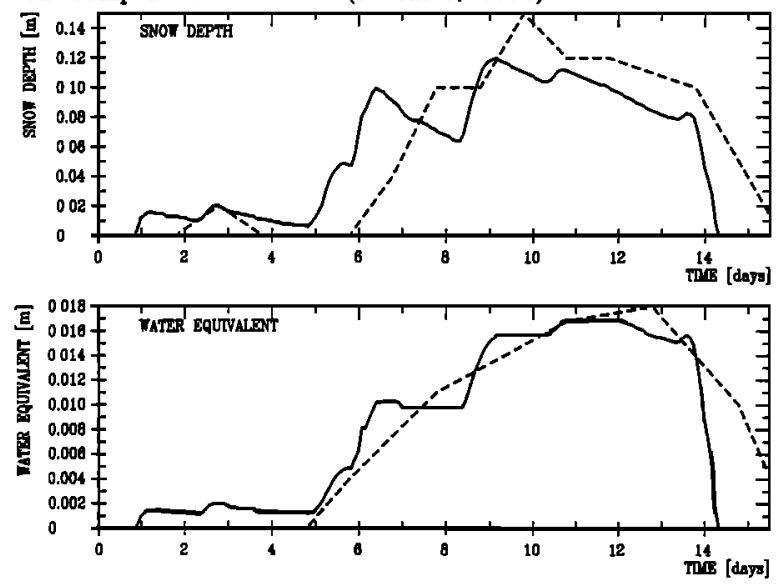

Fig. 8. Simulated snow depth and water equivalent for Potsdam during the time interval November 27, 1980 to December 12, 1980 applying different criteria for the distinction of snowfall and rain. Dashed curve, observations; solid curve, simulations.

model simulation was carried out for the test period (see section 3.1) with a doubled global radiation. This change in radiation is equivalent to a decrease in the melting period after 4 to 5 days caused by albedo.

The comparison of the simulated results with the control run shows no differences in snow depth between the two model versions over the whole period. The water equivalent is reduced after 15.5 days by $1 \mathrm{~cm}$. Whereas the mean daily values of snow surface temperature and energy fluxes remain, the daily amplitudes increase by $1 \mathrm{~K}$ and $1 \mathrm{~W} \mathrm{~m}^{-2}$, respectively.

\subsection{Turbulent Heat Fluxes}

Firstly, we examined the sensitivity of the model to different extrapolations of the wind speed to the reference height of $1 \mathrm{~m}$ which is used in the bulk formulae (compare section 2.3.3). Therefore we used a potential approach suggested by Siemer [1988]:

$$
u_{\text {ref }}=u_{\text {meas }}\left(\frac{h_{\text {ref }}}{h_{\text {meas }}-h}\right)^{1 / 6},
$$

where $h, h_{\text {ref }}$, and $h_{\text {meas }}$ are the snow depth in meters, the reference height of $1 \mathrm{~m}$, and the measurement height of $10 \mathrm{~m}$, respectively, and $u_{\text {ref }}$ and $u_{\text {meas }}$ represent the wind speed at
1 and $10 \mathrm{~m}$, respectively, and a logarithmic wind profile which refers to

$$
u_{\text {ref }}=u_{\text {meas }} \ln \left(\frac{h_{\text {ref }}}{z_{0}}\right) / \ln \left(\frac{h_{\text {meas }}-h}{z_{0}}\right)
$$

where $z_{0}$ is the roughness length and set to $10^{-4} \mathrm{~m}$ [König, 1985].

The input data sets investigated were recorded in Potsdam in the time interval November 27 to December 12, 1980. The simulations show a higher water equivalent of accumulated snow masses ( +2 to $4 \mathrm{~mm}$ ) and an increased snow depth (+1 to $2 \mathrm{~cm}$ ) for the logarithmic wind profile.

The influence of the turbulent heat fluxes was further studied by comparing the results of the bulk method with estimations using the Monin-Obukhov similarity theory. The coefficients were taken from Oberhuber [1990] who originally applied the Monin-Obukhov similarity theory to the energy exchange between atmosphere and ocean. The comparison of the simulations shows no marked change in the snow depth, water equivalent, or snow surface temperature. The latent heat flux increases by $4 \mathrm{~W} \mathrm{~m}^{-2}$. A variation of the sensible heat flux (by $-7 \mathrm{~W} \mathrm{~m}^{-2}$ ) only appears for the temperature decrease after the second time interval. Altogether, the different estimations of the turbulent heat fluxes do not exert a strong influence on the development of the snow profiles.

\section{LONG-Term InTEgrations FOR PotSDAM}

\subsection{Dato}

The observations used for the validation of the snow cover model were carried out at the German meteorological station Potsdam $\left(52^{\circ} 23^{\prime}, 13^{\circ} 04^{\prime}\right)$. This station is located on the northwestern slope of a hill $(81 \mathrm{~m}) 600 \mathrm{~m}$ away from the southern urban boundary of Potsdam. It is surrounded by a forest with predominantly pine trees. The measuring field itself is situated in a clearing of $30 \mathrm{~m} \times 40 \mathrm{~m}$. The soil is characterized by relatively dry conditions. For the choice of the data basis it was borne in mind that in order to avoid special cases the station should not be especially orientated toward measuring snow data and should not show any extreme conditions.

Climatic background: The typical snow depth for Potsdam is in the range of 1 to $10 \mathrm{~cm}$. It is accompanied with water equivalents between 1 and $15 \mathrm{~mm}$. The maximum snow depth was observed in March 1970 (70 cm). Mean extreme values are between 5 and $10 \mathrm{~cm}$ in November and April and $30-50 \mathrm{~cm}$ in February. The new snow depth is usually between 1 and $6 \mathrm{~cm}$, in single cases up to $20 \mathrm{~cm}$. This overview is confined to the period 1950/1980 and based on a climatic survey published in 1988 by the Meteorological Service of the former East Germany.

Measuring frequencies: The required data of air and dew point temperature, air pressure, wind speed, total amount of cloud, type of cloud, and global radiation are taken hourly, whereas the soil temperature is recorded every 3 hours. The precipitation is measured at intervals of 6 hours $(0000,0600$, 1200,1800 UTC). The reference data for snow depth and water equivalent only exist as daily values (0600 UTC).

Measuring methods for the snow depth and water equivalent: The two snow parameters are measured in the 


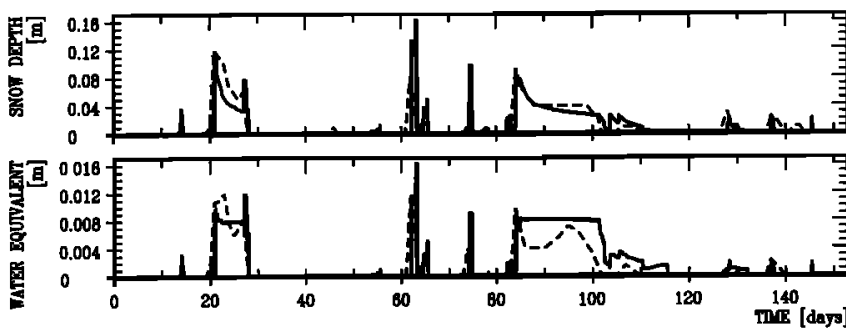

Fig. 9. Simulated snow depth and water equivalent for Potsdam during the winter 1975/1976. Dashed curve, observations; solid curve, simulations.

traditional way at 3 or 4 different places of the measuring field. The snow depth is determined by the ruler with an accuracy of $\pm 1 \mathrm{~cm}$ and the water equivalent is estimated by digging and measuring the volume of the melting water $( \pm 1$ $\mathrm{mm})$. Patchy snow areas are neglected if they cover less than $50 \%$ of the field area. A closed or broken snow cover with a snow depth less than $1 \mathrm{~cm}$ is given that value.

\subsection{Results}

The input data sets cover the time intervals of November 1 to the following April 1 of the years 1975 to 1980. The simulation results (Figure 9 to Figure 14) show a good correspondence between the observations and the modeled values of snow depth and water equivalent. In every phase of the snow cover development the snow properties are generally well reproduced. The time of accumulation and the end of ablation are accurately estimated. This reflects a satisfactory treatment of the physical processes, including the melting and freezing cycles and the alterations due to aging. Especially for the winters 1975/1976 and 1978/1979 we find an encouraging similarity, although the model has not been designed for local studies and no data correction or tuning was performed.

Greater differences occur only when there is a misclassification of the aggregational state of precipitation. In the course of winter 1980/1981, difficulties concerning this problem during the accumulation period lead to an unrealistically deep snow cover during the whole winter (not shown). The simulated beginning of the unrealistic accumulation was at day 62. For day 64 , precipitation at temperatures between $-3^{\circ} \mathrm{C}$ and $-4^{\circ} \mathrm{C}$ was recorded. Because of the snow-rain criterion used, the model mainly interpreted this precipitation as snow. An analysis of the parallel recorded data of snow depth and water equivalent shows, however, that the

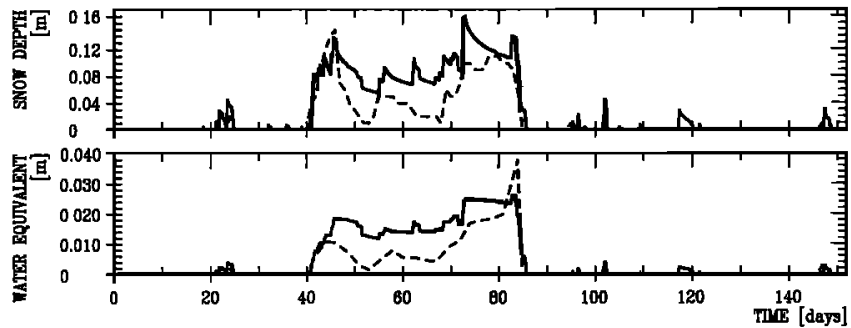

Fig. 10. Simulated snow depth and water equivalent for Potsdam during the winter 1976/1977. Dashed curve, observations; solid curve, simulations.

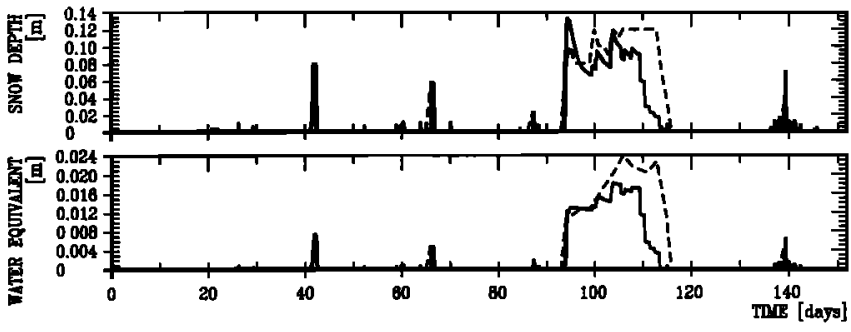

Fig. 11. Simulated snow depth and water equivalent for Potsdam during the winter 1977/1978. Dashed curve, observations; solid curve, simulations.

majority of this precipitation actually fell as rain. Thus we suppose that the measured air temperature is not representative for the air temperature at the moment of rainfall or that the criterion was not suitable for that situation. This sensitive behavior emphasizes the necessity to improve the model at that point.

4.2.1. First period, November 1, 1975, to April 1, 1976 (Figure 9). This winter was characterized by two longer snow intervals (days 20 to 28 and days 84 to 103) and some shallow short-term snowpacks. The model reproduced this development in detail. The deepest snow covers of the longer snow intervals were observed at days 20 and 84 . The model calculates for these days snow depths which differ only by about $1 \mathrm{~cm}$.

4.2.2. Second period, November 1, 1976, to April 1, 1977 (Figure 10). In this winter a snow cover appeared from days 40 to 84 . The simulated snow depth widely corresponds to the observations. Especially the accumulation processes and the end of ablation are realistically simulated.

4.2.3. Third period, November 1, 1977, to April 1, 1978 (Figure 11). In the course of the winter a longer snow interval occurs from days 94 to 115 with a maximum snow depth of $13 \mathrm{~cm}$. Two shallow snow covers $(5$ to $6 \mathrm{~cm}$ ) were recorded at days 66 and 140 . They are sufficiently depicted in both snow depth and water equivalent. The longer period is well represented up to day 107 . The observed increase at day 107 is probably the result of snowdrift because no precipitation was recorded at that time. The simulated ablation beginning at day 109 occurs too rapidly so that the snow cover and water equivalent reduce too quickly.

4.2.4. Fourth period, November 1, 1978, to April 1, 1979 (Figure 12). This winter is characterized by a longer snow cover from days 58 to 132 with some local maxima. In general, the simulation is quite adequate with a high correspondence between the observed and the simulated data. The decrease from days 60 to 65 is the result of the processes

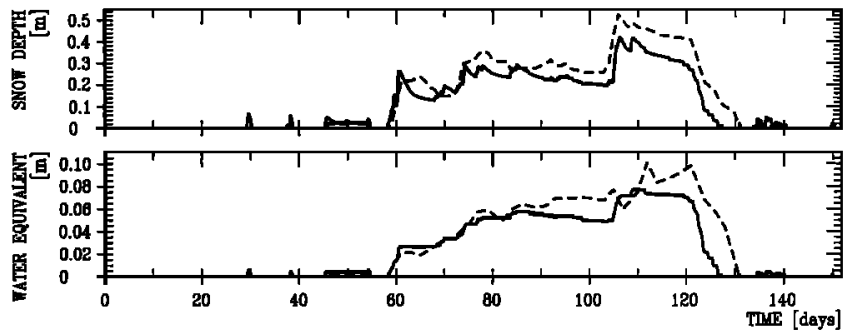

Fig. 12. Simulated snow depth and water equivalent for Potsdam during the winter 1978/1979. Dashed curve, observations; solid curve, simulations. 


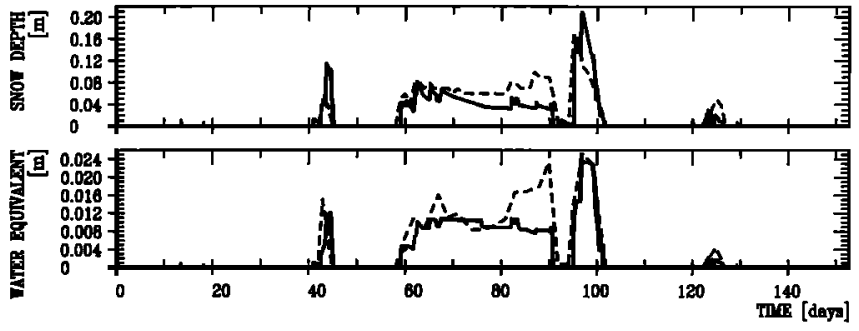

Fig. 13. Simulated snow depth and water equivalent for Potsdam during the winter 1979/1980. Dashed curve, observations; solid curve, simulations.

of metamorphism. The snowfall during that period, however, is interpreted as rain. That avoids the simulation of the observed increase in snow depth. In the ablation period an incorrect determination of the aggregational phase of precipitation initiates a faster decrease of snow depth than in reality.

4.2.5. Fifth period, November 1, 1979, to April 1, 1980 (Figure 13). The snow covers at day 125 and from days 96 to 102 are reproduced in detail. In the other two periods, difficulties in connection with the snow-rain criterion appear in the accumulation period. Thus water equivalent and snow depth have too small values. The increase at day 90 is too small because the modeled rain refers to runoff, whereas in reality new snow was added.

The internal profiles of snow temperature, liquid water content, and snow density for the first snow cover period in
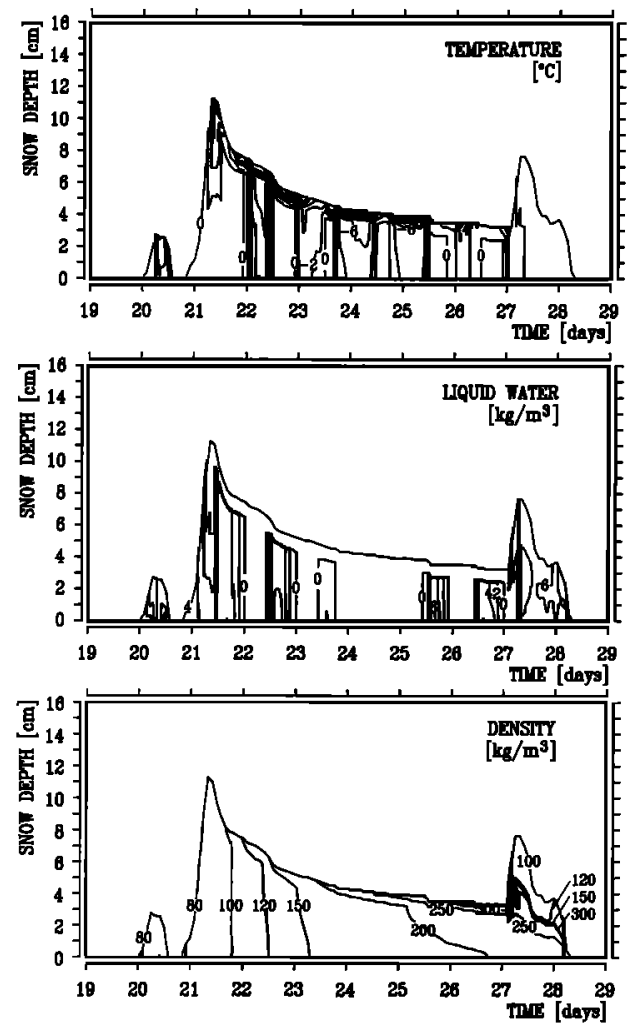

Fig. 14. Internal profiles of snow temperature, liquid water content, and snow density for the winter 1975/1976 during the snow interval days 20 to 28 . winter 1975/1976 are given in Figure 14. Due to the aging processes the snow density increases continuously with time from 80 to about $250 \mathrm{~kg} \mathrm{~m}^{-3}$ in the course of less than 9 days. The values of snow temperature and liquid water content show the characteristic daily cycle of freezing and melting which is induced by the global radiation, the turbulent heat and water vapor fluxes, and the long wave emission. During the ablation period the temperature profile was constant at $273.15 \mathrm{~K}$. Both snow density and liquid water content increase rapidly.

\section{ConClusions}

The purpose of this study was to construct and test a one-dimensional snow cover model being a composition of a detailed physical description of a snowpack and minimum computer time requirement. The model should be applicable globally and in long-term climate simulations.

For this reason the snow cover is considered as a multilayer system consisting of ice, liquid water, water vapor, and air with a minimum depth of $1 \mathrm{~mm}$. As internal processes the heat conduction, water vapor diffusion, absorption of short wave radiation, and the processes of freezing, melting, and aging are simulated using an integration time step of 2 hours. Energy and mass fluxes depending on the snow temperature are implicitly introduced. The equation system for the heat conduction is solved by applying a fully implicit technique suggested by Richtmyer and Morton [1967]. In the melting and freezing scheme a transformation of the coordinates to the mass fluxes of the single components was incorporated to conserve mass and energy.

Long-term integrations for six winters carried out with data sets from Potsdam $\left(52^{\circ} \mathrm{N}, 13^{\circ} \mathrm{E}\right)$ demonstrate a good correspondence between the observations and the simulated values of snow depth and water equivalent. All phases of snow cover development are generally well reproduced. The model is able to cope with deep snow covers $(>0.50 \mathrm{~m})$ as well as with short-occurring shallow ones $(<0.05 \mathrm{~m})$. The times of accumulation and end of ablation are exactly modeled. The similarity, especially for the winters of 1975/ 1976 and 1978/1979, is encouraging because no tuning was performed, local parameterizations were avoided, and no corrections were applied to the standard synoptic measurements used. Therefore the model is not only potentially applicable in global studies but it is also well suited for local simulations.

The remaining problem is the choice of an appropriate criterion for the determination of the aggregational state of precipitation which mainly influences the simulated snow depth and water equivalent. Misclassifications are probable, especially in cases of advection of cold and warm air. A possible solution is the utilization of the "ww" of the international synoptic code as input data. In long-term climatic studies this problem is of less importance.

\section{Nota'TION}

$\alpha$ albedo of snow.

$\alpha_{0}$ clear sky albedo.

$c_{E}$ specific heat capacity of ice, J/( $\left.\mathrm{kg} \mathrm{K}\right)$.

$c_{P}$ specific heat capacity of air for constant $\mathrm{J} /(\mathrm{kg} \mathrm{K})$ pressure.

$c^{R}$ retention capacity.

$c_{S}$ specific heat capacity of dry snow, $\mathrm{J} /(\mathrm{kg} \mathrm{K})$. 
$c_{W} \quad$ specific heat capacity of liquid water, $\mathrm{J} /(\mathbf{k g ~ K})$.

$D$ effective diffusion coefficient for water vapor, $\mathrm{m}^{2}$ $\mathbf{s}^{-1}$.

$d$ grain size, $\mathrm{m}$.

$\varepsilon \varepsilon=R_{a} / R_{V}$.

$\varepsilon_{A}$ emissivity of air.

$\varepsilon_{c}$ emissivity of clouds.

$\varepsilon_{S}$ emissivity of snow.

$e_{A}$ vapor pressure in the atmosphere, $\mathrm{Pa}$.

$e_{S}$ vapor pressure within the snow, $\mathrm{Pa}$.

$h$ snow depth, m.

$\eta_{c}$ compact viscosity, Pa s.

$K$ effective thermal conductivity of snow, $\mathrm{W} /(\mathrm{m} \mathrm{K})$.

$\lambda$ thermal heat conductivity of soil, $\mathrm{W} /(\mathrm{m} \mathrm{K})$.

$L_{F} \quad$ latent heat of fusion, $\mathrm{J} / \mathrm{kg}$.

$L_{S}$ latent heat of sublimation, $\mathrm{J} / \mathrm{kg}$.

$L_{V}$ latent heat of evaporation, $\mathrm{J} / \mathrm{kg}$.

$M^{*}$ mass balance, $\mathrm{kg} /\left(\mathrm{m}^{3} \mathrm{~s}\right)$.

$M_{A}$ outflow, $\mathrm{kg} /\left(\mathrm{m}^{3} \mathrm{~s}\right)$.

$m_{a}$ mass of dry air within the snow cover, $\mathrm{kg}$.

$m_{E}$ mass of ice within the snow cover, $\mathrm{kg}$.

$M_{\mathrm{PR}}$ intensity of rain, $\mathrm{kg} /\left(\mathrm{m}^{3} \mathrm{~s}\right)$.

$M_{\mathrm{PRS}}$ trapped liquid water due to rain, $\mathrm{kg} /\left(\mathrm{m}^{3} \mathrm{~s}\right)$.

$M_{\text {PS }}$ intensity of snowfall, $\mathrm{kg} /\left(\mathrm{m}^{3} \mathrm{~s}\right)$.

$M_{\text {vs }}$ turbulent water vapor flux at the snow surface, $\mathrm{kg} /\left(\mathrm{m}^{3} \mathrm{~s}\right)$.

$M_{V}$ water vapor flux within the snow cover, $\mathrm{kg} /\left(\mathrm{m}^{3}\right.$ s).

$m_{W}$ mass of liquid water within the snow cover, $\mathrm{kg}$.

$N$ cloud amount.

$\nu$ extinction coefficient of snow, $\mathrm{m}^{-1}$.

$p$ surface air pressure, $\mathrm{Pa}$.

$Q^{*}$ energy balance of snow cover, $\mathrm{W} \mathrm{m}^{-2}$.

$Q_{B}$ ground heat flux, $\mathrm{W} / \mathrm{m}^{2}$.

$Q_{\text {ES }}$ latent turbulent heat flux, $\mathrm{W} / \mathrm{m}^{2}$.

$Q_{\mathrm{E}}$ latent heat flux within the snow cover, $\mathrm{W} / \mathrm{m}^{2}$.

$Q_{H}$ sensible heat flux, W/m².

$Q_{\text {HPR }}$ energy input due to rain, $\mathrm{W} / \mathrm{m}^{2}$.

$Q_{L}^{*} \quad$ long wave radiation balance of snow cover, $\mathrm{W} / \mathrm{m}^{2}$.

$Q_{\mathrm{LC}}$ long wave radiation emitted by clouds, $\mathrm{W} / \mathrm{m}^{2}$.

$Q_{S}^{*}$ short wave radiation balance of snow cover, $\mathrm{W} / \mathrm{m}^{2}$.

$Q_{S}$ short wave radiation flux within the snow cover, $\mathrm{W} / \mathrm{m}^{2}$.

$\rho$ snow density, $\mathrm{kg} \mathrm{m}^{-3}$.

$R_{a}$ gas constant of dry air, $\mathrm{J} /(\mathrm{kg} \mathrm{K})$.

$R_{V}$ gas constant of water vapor, $\mathrm{J} /(\mathrm{kg} \mathrm{K})$.

$\sigma$ Stefan-Boltzmann constant, $W /\left(\mathrm{m}^{2} \mathrm{~K}^{4}\right)$.

$\Theta$ zenith angle of Sun, rad.

$T$ snow temperature, $\mathrm{K}$.

$t$ time, s.

$t_{A}^{8-14}$ transmissivity of atmosphere in the wave length interval 8-14 $\mu \mathrm{m}$.

$T_{0}$ melting temperature, $\mathrm{K}$.

$T_{A}$ air temperature, $\mathrm{K}$.

$T_{B}$ soil temperature, $\mathrm{K}$.

$T_{c}$ cloud temperature at the bottom, $\mathrm{K}$.

$T_{P}$ temperature of precipitation, $\mathrm{K}$.

$T_{S}$ snow surface temperature, $\mathrm{K}$.

$v$ water vapor concentration, $\mathrm{kg} \mathrm{m}^{-3}$.

$w$ liquid water content, $\mathrm{kg} \mathrm{m}^{-3}$

$\psi$ elevation angle of Sun, rad.

\section{REFERENCES}

Anderson, E. A., A point energy and mass balance model of a snow cover, NOAA Tech. Rep. NWS 19, p. 150, U.S. Dept. of Commer., Washington, D. C., 1976.

Barnett, T. P., L. Dümenil, U. Schlese, E. Roeckner, and M. Latif, The effect of Eurasian snow cover on regional and global climate, large-scale modelling, Tech. Rep. 5, p. 56, Meteorol. Inst. der Univ. Hamburg, Germany, 1988.

Bauer, H., E. Heise, J. Pfaendtner, V. Renner, and P. Schmidt, Entwicklung und Erprobung eines ökonomischen Modells zur Vorhersage von Oberflächenparametern in Rahmen eines Klimamodells (Development and testing of an economic model for the prediction of surface parameters in climate models), final report, Res. Dep. Ger. Weather Serv., Offenbach, 1983.

Bohren, C. F., and B. R. Barkstrom, Theory of the optical properties of snow, J. Geophys. Res., 79(30), 4527-4535, 1974.

Choudhury, B. J., and A. T. C. Chang, The albedo of snow for partially cloudy skies, Boundary Layer Meteorol., 20, 371-389, 1981.

Dickinson, R. E., A. Henderson-Sellers, P. J. Kennedy, and M. F. Wilson, Biosphere-atmosphere transfer scheme for the NCAR community climate model, NCAR Tech. Note, NCAR TN$275+S T R$, p. 69, Natl. Cent. for Atmos. Res., Boulder, Colo., 1986.

Dirmhirn, I., Einiges über die Reflexion der Sonnen- und Himmelsstrahlung an verschiedenen Oberflächen (Comments on the reflection of solar and diffuse radiation at different surfaces), Wetter Leben, 5(3/4), 86-94, 1953.

Dirmhirn, I., and F. D. Eaton, Some characteristics of the albedo of snow, J. Appl. Meteorol., 14(3), 375-379, 1975.

Dunkle, R. U., and J. T. Bevans, An approximate analysis of the solar reflectance and transmittance of a snow cover, J. Meteorol., 13(4), 212-216, 1956.

Flohn, H., Background of a geophysical model of the initiation of the next glaciation, Quat. Res., 4, 385-404, 1974.

Garratt, J. R., The Atmospheric Boundary Layer, pp. 87-88, Cambridge University Press, New York, 1992.

Graf, H. F., Response of the T21-atmosphere to a north-polar global radiation deficit, in Climate Simulations With the ECMWF T21 Model in Hamburg, part III, Diagnosis of Response Experiments, Large-Scale Atmospheric Modelling, Tech. Rep. 7, pp. 211-232, Meteorol. Inst. der Univ. Hamburg, 1989.

Gray, D. M., and P. G. Landine, Albedo model for shallow prairie snow covers, Can. J. Earth Sci., 24, 1760-1768, 1987.

Gunn, K. L. S., Measurements on new-fallen snow, Stormy Weather Group, Sci. Rep. MW-44, p. 62, McGill Univ., Montreal, Quebec, 1965.

Hahn, D. J., and J. Shukla, An apparent relationship between Eurasian snow cover and Indian monsoon rainfall, J. Atmos. Sci., $33,2461-2462,1976$.

Heim, R., and K. F. Dewey, Circulation patterns and temperature fields associated with extensive snow cover on the North American continent, Phys. Geogr., 4, 66-85, 1984.

Idso, S. B., A set of equations for full spectrum and 8-14 $\mu \mathrm{m}$ and 10.5-12.5 $\mu \mathrm{m}$ thermal radiation from cloudness skies, Water Resour. Res., 17(2), 295-304, 1981.

Kimball, B. A., S. B. Idso, and J. K. Aase, A model of thermal radiation from partly cloudy and overcast skies, Water Resour. Res., 18(4), 931-936, 1982.

Kojima, K., Densification of a seasonal snow cover, in Physics of Snow and Ice, Proc. Int. Conf. Low Temp. Sci., vol. I, part 2, S.929-S.952, 1967.

Konig, G., Roughness length of an Antarctic ice shelf, Polarforschung, 55(1), 27-32, 1985.

Ledley, T. S., Snow on sea ice: Competing effects in shaping climate, J. Geophys. Res., 96(D9), 17,195-17,208, 1991.

Liljequist, G. H., Energy Exchange of an Antarctic Snow Field, Norwegian-Swedish Antarctic Expedition, 1949-1952, II, Scientific Results, pp. 83-91, Norsk Polarinstitut, Oslo, 1956.

Mellor, M., Properties of snow, Cold Reg. Sci. Eng. Monogr., III-AI, p. $105,1964$.

Oberhuber, J. M., Simulation of the Atlantic circulation with a coupled sea ice-mixed layer-isopycnal general circulation model, Tech. Rep. 59, pp. 19-25, Max-Planck-Inst. für Meteorol., Hamburg, Germany, 1990. 
Petzold, D. E., Estimation technique for snow surface albedo, Climatol. Bull., 21, 1-11, 1977.

Rachner, M., Versuch einer Schätzung der Schneehöhe mit Hilfe von Simulationsmodellen (attempt to estimate the snow depth by means of simulation models), Z. Meteorol., 33(4), 234-243, 1983.

Richtmyer, R. D., and K. W. Morton, Difference Methods for Initial-Value Problems, John Wiley, New York, 1967.

Rohrer, M., Determination of the transition air temperature from snow to rain and intensity of precipitation, in Proceedings of the St. Moritz Symposium on Precipitation Measurement, Dec. 4-7, edited by B. Sevruk, pp. 475-482, 1989.

Siemer, A. H., Eindimensionales EBM einer Schneedecke unter Berücksichtigung der Flüssigwassertransmission (One-dimensional EBM of a snow cover taking into account liquid water transmission), Ber. Inst. Meteorol. Klimatol. Univ. Hannover, 34 $126,1988$.

Sommerfeld, R. A., and E. La Chapelle, The classification of snow metamorphism, J. Glaciol, 9(55), 3-17, 1970.

Stull, R. B., An Introduction to Boundary Layer Meteorology, 666 pp., Kluwer Academic, Hingham, Mass., 1988.

Verseghy, D. L., CLASS-A Canadian land surface scheme for GCMs, I, Soil model, J. Climatol., 11, 111-133, 1991.
Walsh, J. E., W. H. Jasperson, and B. Ross, Influences of snow cover and soil moisture on monthly air temperature, Mon. Weather Rev., 113, 756-768, 1985.

Wilhelm, F., Schnee- und Gletscherkunde (Snow and Glaciology), 434 pp., de Gruyer, Berlin, 1975.

Wiscombe, W. J., and S. G. Warren, A model for the spectral albedo of snow, I, Pure snow, J. Atmos. Sci., 37, 2712-2733, 1980.

World Meteorological Organization (WMO), Intercomparison of models of snowmelt runoff, WMO Oper. Hydrol. Rep. 23, WMO Publ. 646, Geneva, 1986.

Yen, Y.-C., Recent studies on snow properties, in Advances in Hydroscopy, pp. 173-214, Academic, San Diego, Calif., 1969.

H.-F. Graf and B. Loth, Max-Planck-Institut für Meteorologie, Bundesstrasse 55, 2000 Hamburg 13, Germany.

J. M. Oberhuber, Meteorologisches Institut, Universität Hamburg, Hamburg, Germany.

(Received August 14, 1992;

revised January 25, 1993;

accepted January 31, 1993.) 